\title{
FOURIER MULTIPLIER THEOREMS FOR BESOV AND TRIEBEL-LIZORKIN SPACES WITH VARIABLE EXPONENTS
}

\author{
TAKAHIRO NOI
}

Abstract. In this paper, we will prove Fourier multiplier theorems on Besov and Triebel-Lizorkin spaces with variable exponents. It was shown by many authors that variable Triebel-Lizorkin spaces coincide with variable Bessel potential spaces, variable Sobolev spaces and variable Lebesgue spaces when appropriate indices are chosen. In consequence of the results, we also have Fourier multiplier theorems on these variable function spaces.

Mathematics subject classification (2010): 42B15.

Keywords and phrases: Fourier multiplier theorem, variable exponents Besov spaces, variable exponents Triebel-Lizorkin spaces.

\section{REFERENCES}

[1] A. Almeida And P. Hëstö, Besov spaces with variable smoothness and integrability, J. Funct. Anal. 258, 5 (2010), 1628-1655.

[2] D. Cruz-Uribe, SFO, A. Fiorenza, J. M. Martell and C. PÉrez, The boundedness of classical operators on variable $L^{p}$ spaces, Ann. Acad. Sci. Fenn. Math. 31 (2006), 239-264.

[3] D. Cruz-Uribe, SFO, A. Fiorenza And C. J. Neugebauer, The maximal function on variable $L^{p}$ spaces, Ann. Acad. Sci. Fenn. Math. 28 (2003), 223-238.

[4] L. Diening, Maximal function in generalized $L^{p(\cdot)}$ spaces, Math. Inequal. Appl. 7 (2004), 245-253.

[5] L. Diening, Maximal function on Musielak-Orilcz spaces and generalized lebesgue spaces, Bull. Sci. Math. 129 (2005), 657-700.

[6] L. Diening, P. Harjulehto, P. Hästö And M. RŮŽIČKA, Legesue and Sobolev Spaces with Variable Exponents, Springer, Lecture Notes in Mathematics 2017, Springer (2011).

[7] L. Diening, P. HÄSTÖ AND S. Roudenko, Function spaces of variable smoothness and integrability, J. Funct. Anal. 256, 6 (2009), 1731-1768.

[8] L. DIENING AND M. RŮŽIČKA, Calderón-Zygmund operators on generalized Lebesgue spaces $L^{p(\cdot)}$ and problems related to fluid dynamics, J. Reine Angew. Math. 563 (2003), 197-220.

[9] P. Gurka, P. Harjulehto And A. NekVinda, Bessel potential spaces with variable exponent, Math. Inequal. Appl. 10, 3 (2007), 661-676.

[10] H. KempKa, 2-microlocal Besov and Triebel-Lizorkin spaces of variable integrability, Rev. Mat. Complut. 22, 1 (2009), 227-251.

[11] H. KEMPKA AND J. VyBíRAL, Spaces of variable smoothness and integrability: Characterizations by local means and ball means of differences, J. Fourier Anal. Appl., 18, (2012) 852-891.

[12] O. KovÁČIK AND J. RÁKosNíK, On spaces $L^{p(x)}$ and $W^{k, p(x)}$, Czech. Math. J. 41 (1991), 592-618.

[13] L. PICK AND M. RŮŽIČKA, An example of a space $L^{p(\cdot)}$ on which the Hardy-Littlewood maximal operator is not bounded, Expo. Math. 19 (2001), 369-371.

[14] S. G. Samko, Differentiation and Integration of Variable Order and the Spaces $L^{p(x)}$, Contemp. Math. 212 (1998), 203-219.

[15] E. M. Stein, Harmonic analysis, Princeton University Press, 1993.

[16] H. TRiebel, Theory of Function Spaces, Birkhäuser, Basel, Boston, 1983.

[17] J. VybíRAL, Sobolev and Jawerth embeddings for spaces with variable smoothness and integrability, Ann. Acad. Sci. Fenn., Math. 34, 2 (2009), 529-544. 
[18] J. XU, The relation between variable Bessel potential spaces and Triebel-Lizorkin spases, Integral Transforms Spec. Funct. 19 (2008), 599-605.

[19] J. Xu, Variable Besov and Triebel-Lizorkin spaces, Ann. Acad. Sci. Fenn. Math. 33 (2008), 512-522.

[20] J. Xu, An atomic decomposition of variable Besov and Triebel-Lizorkin spaces, Armen. J. Math. (2009), 1-12. 